University of South Carolina

Scholar Commons

$7-2010$

\title{
A Miniature Energy Harvesting Device for Wireless Sensors in Electric Power System
}

\author{
Rashed H. Bhuiyan \\ University of South Carolina - Columbia, bhuiyan@cec.sc.edu \\ Roger A. Dougal \\ University of South Carolina - Columbia, dougal@engr.sc.edu \\ Mohammod Ali \\ University of South Carolina - Columbia, alimo@engr.sc.edu
}

Follow this and additional works at: https://scholarcommons.sc.edu/elct_facpub

Part of the Electrical and Computer Engineering Commons

\author{
Publication Info \\ Published in IEEE Sensors Journal, Volume 10, Issue 7, 2010, pages 699-702. \\ http://ewh.ieee.org/tc/sensors/SJ/Sensors_journal.htm \\ (C) 2010 by IEEE
}

This Article is brought to you by the Electrical Engineering, Department of at Scholar Commons. It has been accepted for inclusion in Faculty Publications by an authorized administrator of Scholar Commons. For more information, please contact digres@mailbox.sc.edu. 


\title{
A Miniature Energy Harvesting Device for Wireless Sensors in Electric Power System
}

\author{
Rashed H. Bhuiyan, Student Member, IEEE, Roger A. Dougal, Senior Member, IEEE, and \\ Mohammod Ali, Senior Member, IEEE
}

\begin{abstract}
A novel energy harvesting device called the energy coupler is proposed which can provide power to small wireless sensors in a power system. The energy coupler when coupled electromagnetically to a nearby current carrying conductor scavenges ac power from the conductor. The proposed energy coupler converts the harvested ac power into dc using a passive voltage multiplier circuit. The design of the energy coupler is such that the dc power obtained is adequate to charge a miniature $1.2-\mathrm{V}$ rechargeable battery. It is demonstrated that the energy coupler is capable of delivering $10 \mathrm{~mW}$ of dc power to a $50-\Omega$ load. An analytical model is also presented which agrees well with measurement results within a margin of error of $10 \%$.
\end{abstract}

Index Terms-Effective permeability, energy coupler, energy harvesting, sensor.

\section{INTRODUCTION}

$\mathbf{M}$ ONITORING line conditions, disturbances, and faults is essential to ensure proper operation of a power system. Autonomous wireless sensors are key future elements which will enable such monitoring simple, easy and cost effective. Such sensors will probe the necessary currents, voltages, and insulation properties of a power line in a non-intrusive manner and then relay such data to a decision station wirelessly. Some examples of sensors requiring power of $10 \mathrm{~mW}$ or lower can be found in [1]-[4]. The sensor proposed in [1] was integrated with a $1.863 \mathrm{GHz}$ transmitter which needed $1.35 \mathrm{~mW}$ of power. PicoRadio [2], a low-power transceiver module, requires $1.6 \mathrm{~mW}$ in the transmit mode. At $433 \mathrm{MHz}$ the $2.1 \mathrm{~V}$ Chipcon CC1000 [3] transceiver draws $7.4 \mathrm{~mA}$ in the receive mode and $5.3 \mathrm{~mA}$ in the transmit mode. The MSP430 is a 16-bit microcontroller running at $4 \mathrm{MHz}$ with only $0.5 \mathrm{~mW}$ active power consumption [4]. Low-power wireless sensors can rely on high capacity batteries for years. However, to keep the sensor size and cost to minimal, the energy needs of sensors should be met by miniature cheap batteries (e.g., coin cell batteries). Since smaller batteries have limited capacity they must be recharged from time to time.

A good option for solving the energy needs associated with wireless sensors is to scavenge energy from the ambient

Manuscript received July 24, 2009; revised October 14, 2009 and December 20, 2009; accepted December 23, 2009. Date of current version May 21, 2010. This work was supported in part by the U.S. Office of Naval Research under Grant N00014-02-1-0623. The associate editor coordinating the review of this paper and approving it for publication was Prof. Okyay Kaynak.

The authors are with the Department of Electrical Engineering, University of South Carolina, Columbia, SC 29208 USA (e-mail: bhuiyan@cec.sc.edu; dougal@cec.sc.edu; alimo@cec.sc.edu).

Color versions of one or more of the figures in this paper are available online at http://ieeexplore.ieee.org.

Digital Object Identifier 10.1109/JSEN.2010.2040173 environment. This may include scavenging energy using solar, vibrational, thermal, acoustic and electromagnetic mechanisms. Randall [5] showed the use of photovoltaic technology specifically applicable to indoor lighting environments. Lee $e t$ al. [6] showed that by using moving magnets through a coil and a spring for a resonant structure, vibrational energy could be converted resulting in up to $830 \mu \mathrm{W}$ of power. Shenck and Paradiso [7] focused on scavenging power from human movement. They built shoe inserts that generated $8.4 \mathrm{~mW}$ of power during normal walking condition. Stordeur and Stark [8] have demonstrated a thermoelectric device that can produce $15 \mathrm{~mW}$ of power from a $10^{\circ} \mathrm{C}$ temperature differential. Williams et al. [9] developed an electromechanical model for electromagnetic generators. Meninger et al. [10] presented an electrostatic generator that employed a variable micromachined capacitor design with simulated power outputs in the range of tens of $\mu \mathrm{W}$ per cubic centimeter. Ottman et al. [11] designed an optimized power circuitry for a piezoelectric vibration generator. Leland et al. [12] developed a device that could scavenge energy from an existing power system. The device was constructed from cantilever-mount piezoelectric bimorphs and $\mathrm{NdFeB}$ (Neodymium Iron Boron alloy) permanent magnets which coupled magnetic fields of a cable to a conducting ac current. They showed that their device could harvest $208 \mu \mathrm{W}$ and $345 \mu \mathrm{W}$ of power from cables carrying $9.4 \mathrm{~A}$ and $13 \mathrm{~A}$ currents, respectively. However, the focus of this paper is to design and develop an energy harvesting scheme that exploits the well known principle of electromagnetic (EM) induction. Wireless power transfer by EM induction has been investigated by many researchers for various applications. Some examples can be found in [13]-[22]. Specifically, Hirai et al. [13] proposed a scheme to transfer power wirelessly to motor drives. Sergeant and Bossche [14] transferred power without contact to a moving vehicle. Both [13] and [14] used the principle of inductive coupling for wireless power transmission. Similarly, sensors have been developed that measure the line current by probing the magnetic field [23]-[25]. For example, power donuts have been proposed to measure line currents, conductor temperature, and ambient air temperature [24]. It is also possible to self power the power donut [25] but in that case its application will be limited due to its large size. Except for the work reported in [12] and [25], none of the above works focused on energy harvesting for sensors directly from power systems. Moreover, most of the schemes presented in the literature are either unsuitable for implementation in a power system or cannot provide enough power to operate wireless sensors.

This paper presents a novel embodiment called the energy coupler using which wireless sensors can harvest energy from a current carrying conductor in a power system. The energy cou- 
pler is constructed by winding hundreds of turns of very thin conducting wires around a core made by shaping a few layers of flexible high permeability magnetic materials (mu-metals) in cylindrical form. An intentional gap in the flexible core allows the energy coupler to be formed in an agreeable shape to enclose a power line conductor ensuring maximum magnetic flux coupling. A comparable (but not identical) structure to this energy coupler is a Rogowski coil. However, if a small Rogowski coil is used, it will harvest very low-power because of its material construction which contains an air core [26]-[28]. The induced voltage is so low that an active integrating device will be needed to enhance that voltage. The active integrating device itself will consume energy. On the other hand, a large size Rogowski coil [25] will not be convenient for most miniature sensor devices. If they are used with a large number of wireless distributed sensors on an overhead power line their weight can easily create additional undesired sag. The proposed energy coupler is miniature, low cost, and can be easily integrated with a wireless sensor.

In addition to the experimental design, fabrication, and characterization of the energy coupler, this paper develops a theoretical model to understand the flux linkage aspects to the coupler from the primary conductor. Using our proposed theoretical model the induced ac voltage in the energy coupler can be calculated for cores constructed from multi-layer high permeability magnetic materials with small core gaps. In the literature, there are examples of theoretical models to analyze the performance of coils on solid magnetic cores with core gaps [29], [30]. The model given in [29] describes how a gap in the core changes the permeability of the solid core and hence affects the voltage induced in the coil. This model ignores the effects of the fringing flux across the core gap. An improved model given in [30] incorporates the effects of the fringing flux across the core gap. In this work we present a new modified model that considers both the effects, namely the fringing flux across the core gap and the interlayer air gaps present in a core consisting of multiple layers of very thin magnetic materials.

This paper is organized as follows. Section II describes the design and construction details of the proposed energy coupler. A theoretical analysis is presented in Section III. Section IV gives a detailed description of the measurement setup, experimental methods, and theoretical and experimental results. The ac voltage performance found from the measurements and the analytic models are compared. The dc performance obtained from PSpice simulations and measurements are also explained in this section. Finally, Section V concludes this paper.

\section{Device Configuration}

The proposed energy coupler consists of a multiturn coil wound against a magnetic core material constructed from several layers of high permeability mu-metal and an integrated voltage multiplier. The construction of the coil on the magnetic core is illustrated in Fig. 1. A few flexible foils of mu-metal are stacked up to form a laminated core. The typical foil thickness is 4 mils $(0.1016 \mathrm{~mm})$ and the permeability of the mu-metal is $10^{5}$ [31]. The core is shaped as a cylinder in such a way that there is a very small core gap. A very thin wire (diameter $=0.255 \mathrm{~mm}$ ) is wound around the core such that the wires are parallel to the cylinder axis. The power line conductor or the structure containing a conductor bundle goes through the

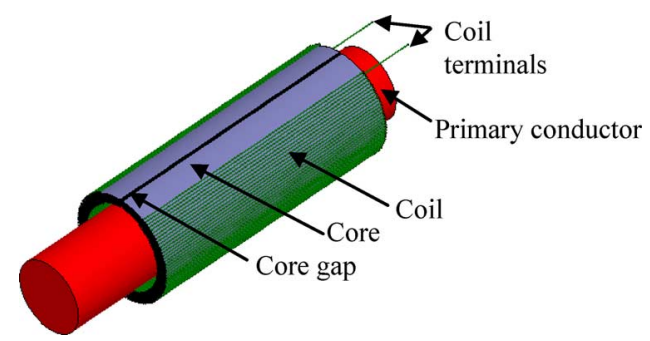

Fig. 1. Multiturn coil on a magnetic core around a current carrying conductor.

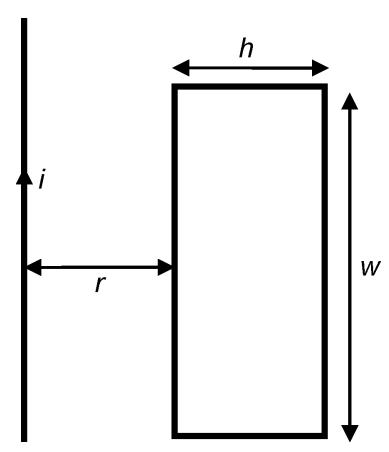

Fig. 2. Rectangular coil near a current carrying conductor.

energy coupler aperture, as shown in Fig. 1. The capability of wrapping around the current carrying conductor is of great importance. If the core is a solid structure, it will have to be put on the cable during the cable manufacturing process. Alternatively, the cable has to be disconnected from the power source which is undesirable because it will disrupt continuous power supply. The presence of the core gap eliminates these two problems and allows greater flexibility in placing the sensor anywhere along the cable. The energy coupler scavenges ac power from the power cable electromagnetically. The ac voltage induced in the coil can be measured across the coil terminals. The output ac voltage of the energy coupler is converted to dc using a voltage multiplier. The dc output of the voltage multiplier charges a rechargeable battery. The details of the voltage multiplier are discussed later.

\section{THEORETICAL ANALYSIS}

The induced ac voltage in the coil is the most important quantity because the dc power available at the multiplier output is dependent on this voltage. In this section, we develop an analytic model which can be used to calculate the induced ac voltage in the coil. We will first start with a simple expression for the induced voltage in a single turn coil and develop it considering the factors affecting it in order to approach the real situation. Consider the rectangular coil made of metal wire in free-space, as shown in Fig. 2. A conductor carrying an alternating current $i$ is placed at a distance $r$ from one side of the coil. If the coil is wound around a magnetic material with width, height and relative permeability of $w, h$ and $\mu_{r}$, respectively, then the magnetic flux linking the coil is [31]

$$
\phi=\frac{\mu_{0}}{2 \pi} \mu_{r} w i \ln \left(1+\frac{h}{r}\right)
$$




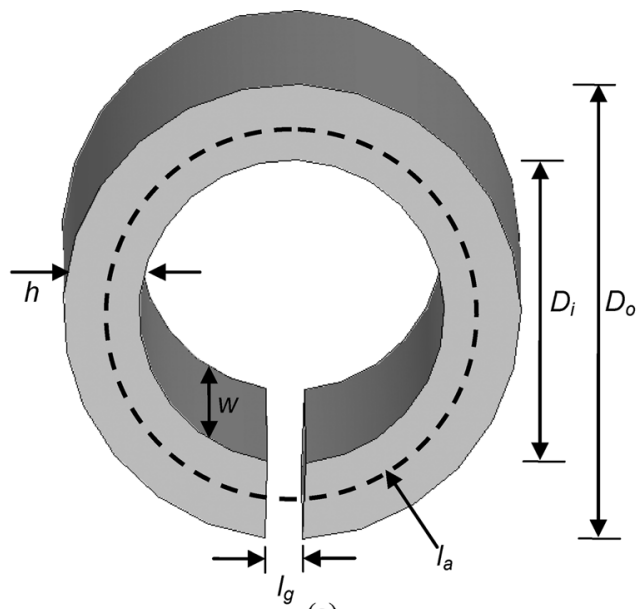

(a)

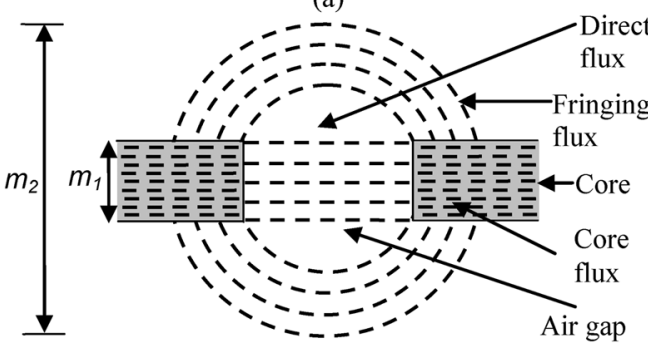

$m_{1}=$ actual core gap width, $m_{2}=$ increased core gap width due to fringing flux

(b)

Fig. 3. (a) Magnetic core with core gap and (b) fringing flux across the core gap. (Figures are not to scale.)

where $\mu_{0}=4 \pi \times 10^{-7}(\mathrm{H} / \mathrm{m})$ is the permeability of free-space. Thus, if an $N$ turn coil is wound around the core encircling the current carrying conductor, as seen in Fig. 1, then the voltage induced in the coil terminals is given by

$$
v=-N \frac{d \phi}{d t}
$$

Using (1) and (2), the root mean square (rms) value of the induced voltage is found as

$$
V=N \mu_{0} \mu_{r} w f I \ln \left(1+\frac{h}{r}\right)
$$

where $f$ and $I$ are the frequency and rms magnitude of the current, respectively. The limitation of (3) is that it ignores the effect of the gap that exists in the core. Our proposed energy coupler has a magnetic core with core gap. Core gaps have very high reluctances compared to the mu-metal and hence reduce the flux linking the core. This represents a significant change in effective permeability (of the core with gap). Fig. 3(a) shows the magnetic core with a core gap where the core gap length is $l_{g}$.

In the literature, two models can be found which incorporate the effect of core gaps. The most common and simplified model [29] approximates the relative permeability as

$$
\mu_{r g}=\frac{\mu_{r}}{1+\left(\frac{l_{g}}{l_{m}}\right) \mu_{r}}
$$

where $\mu_{r g}$ is the effective permeability of the medium considering the core gap, $l_{g}$ is the length of the core gap and $l_{m}$ is the

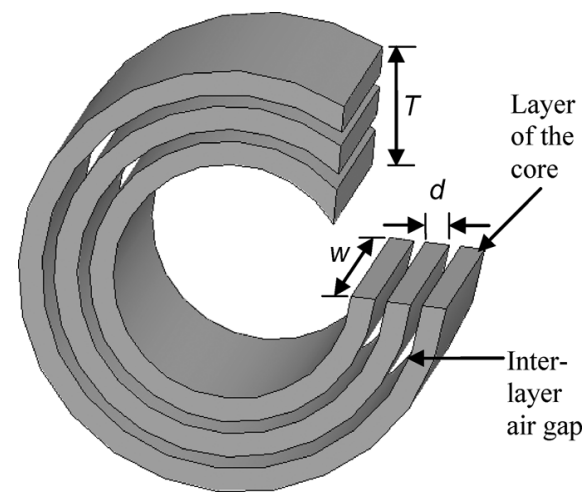

Fig. 4. Multilayer core structure.

mean length of the magnetic path in the core. The parameter $l_{m}$ is found as $\left(l_{a}-l_{g}\right)$, where $l_{a}$ is the mean length of the magnetic field lines along the core including the core gap. If $D_{o}$ and $D_{i}$ are the outer and inner diameters of the core and $D_{o} / D_{i}$ is greater than 1.1 , then a more accurate value for $l_{a}$ can be calculated as [32]

$$
l_{a}=\frac{\pi\left(D_{0}-D_{i}\right)}{\ln \left(\frac{D_{0}}{D_{i}}\right)} .
$$

It will be shown later that the model in (4) underestimates the value of the effective permeability. This is because it does not incorporate the effect of the fringing flux across the air gap, as shown in Fig. 3(b). The fringing flux increases the effective width of the core gap from $m_{1}(=w)$ to $m_{2}$. This effect decreases the reluctance of the core gap and since permeability is inversely related to reluctance hence the effective permeability decrease will not be as pessimistic as in (4). If we consider the effect of the fringing flux, then the effective permeability can be approximated as [30]

$$
\mu_{r g}=\frac{C}{\frac{A}{\frac{A}{l_{g}}+\left(0.241+\frac{1}{\pi} \ln \frac{b}{l_{g}}\right) P}+\frac{C}{\mu_{r}}}
$$

where $C=l_{m} / A, A$ is the cross-sectional area of the core, i.e., $A=h \cdot w$ [Fig. 3(a)], $P$ is the perimeter of the cross section of the core, i.e., $P=2(h+w), b$ is half the inside perimeter of the toroidal core i.e., $b=\pi D_{i} / 2$ [33]. According to [30], the accuracy of the model described by (6) for pot core structures is within $2 \%$ provided $l_{g}$ is shorter than the $w$ and $b / l_{g}$ is larger than about 5 .

The difference between (4) and (6) can be understood if we rewrite (6) in a similar form as (4)

$$
\mu_{r g}=\frac{\mu_{r}}{1+\left(\frac{l_{g}}{l_{m}}\right) \mu_{r}\left[\frac{1}{1+\frac{l_{g}}{A}\left(0.241+\frac{1}{\pi} \ln \frac{b}{l_{g}}\right) P}\right]} .
$$

The term in the square bracket in the denominator of (7) is always less than 1 , so $\mu_{r g}$ in (7) is always larger than $\mu_{r g}$ in (4).

Since in our case, a few thin layers of the magnetic material were stacked up in order to achieve a flexible core structure there will be interlayer air gaps, as shown in Fig. 4, which will reduce the effective permeability of the core. The effects of the interlayer air gaps can be better understood if we explain it using a 


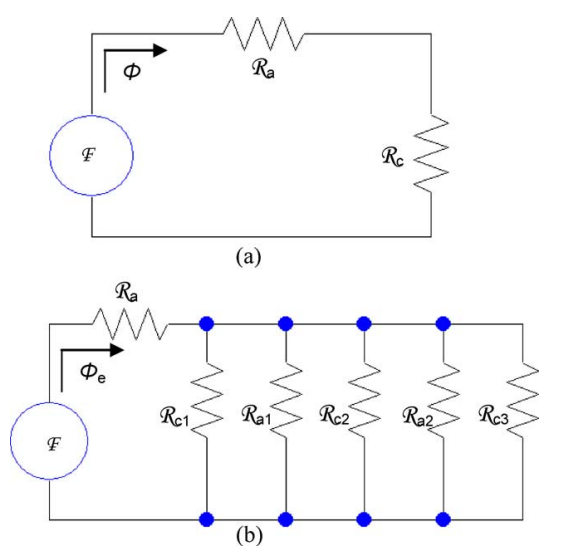

Fig. 5. Circuital representation of (a) single-layer core and (b) multilayer core.

circuital approach. Fig. 5(a) and (b) show that approach for the core configurations in Figs. 3(a) and 4. In Fig. 5, $\mathcal{F}$ is the magnetomotive force (mmf) which is causing the flux $(\Phi)$ to flow through the core. $\mathcal{R}_{a}$ and $\mathcal{R}_{c}$ in Fig. 5(a) are the reluctances due to the core gap and magnetic core, respectively. It is to be noted that

$$
\mathcal{R}=\frac{l}{\mu A}
$$

where $l$ is the length and $A$ is the cross-sectional area of the magnetic path. Now when a multilayer core is used as in Fig. 4, the core layers and the interlayer air gaps each offers different reluctances and the combination acts like a circuit having parallel reluctances as in Fig. 5(b). Since for each core layer $A=w \cdot d$ with $d<h$; each layer gives higher reluctance than the reluctance $\mathcal{R}_{c}$ given by a single core structure. For the interlayer air gap, the permeability is very low, and hence the reluctances $\mathcal{R}_{a 1}$ and $\mathcal{R}_{a 2}$ are very high. Therefore, the equivalent reluctance in Fig. 5(b) will be higher than that in Fig. 5(a). Hence, the multilayer core has lower effective permeability than the single-layer core.

To incorporate the effect of a layered core material with air gaps in between the layers we propose to modify (6). If there are $n$ mu-metal layers in the core, then there are $(n-1)$ interlayer gaps. If $\mathcal{R}_{a}$ and $\mathcal{R}_{r g}$ are the reluctances of the interlayer air gap and mu-metal layer with core gap, respectively, then the equivalent reluctance $\mathcal{R}_{\text {rgn }}$ of the layered core is found from

$$
\frac{1}{\mathcal{R}_{\text {rgn }}}=(n-1) \frac{1}{\mathcal{R}_{a}}+n \frac{1}{\mathcal{R}_{r g}} .
$$

Using (8) in (9)

$$
\frac{\mu_{0} \mu_{r g n} A_{r g n}}{l}=(n-1) \frac{\mu_{0} \mu_{a} A_{a}}{l}+n \frac{\mu_{0} \mu_{r g} A_{m}}{l}
$$

where $\mu_{a}$ and $\mu_{r g}$ are the relative permeabilities of the interlayer air gaps and the mu-metal with core gap, respectively; $\mu_{\text {rgn }}$ is the effective permeability of the core and $A_{r g n}, A_{a}$, and $A_{m}$ are the cross sectional areas of the core, the interlayer air gap and the mu-metal layer, respectively, and $l$ is the length of the magnetic path. If $T, t$ and $d$ are the thicknesses of the core, the interlayer air gap and the mu-metal layer, respectively, then

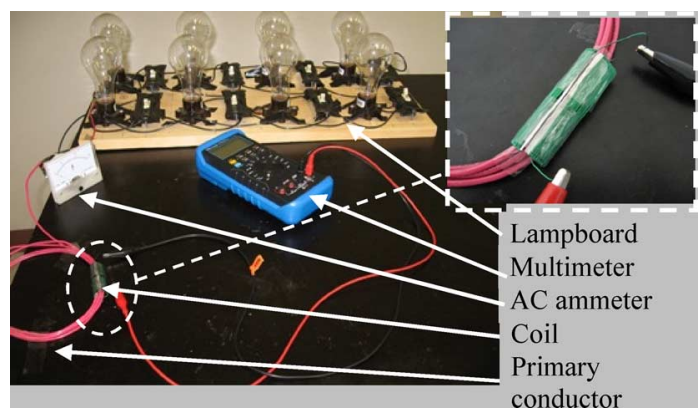

Fig. 6. Experimental setup for output ac voltage measurement (inset shows the close shot of the coil of the energy coupler).

$A_{\text {rgn }}=w T, A_{a}=w t$, and $A_{m}=w d$. Also, $T=[n d+(n-$ 1)t]. Simplifying (10), we get

$$
\mu_{r g n}=1+\left(\mu_{r g}-1\right) \frac{n d}{T} .
$$

The output voltage of the energy coupler can be calculated from (3) by replacing $\mu_{r}$ with $\mu_{r g n}$ obtained from (11) which uses the $\mu_{r g}$ in (6).

\section{Measurements AND Results}

Measurements on the proposed energy coupler were done in two stages. First, the induced ac voltage was measured across the coil terminals with no load connected to it. Second, experiments were performed to evaluate the dc performance of the energy coupler.

On the theoretical side the induced voltage was calculated using three models which are defined below.

Model (4): induced voltage obtained from (3) where $\mu_{r}$ is replaced by $\mu_{r g}$ given in (4).

Model (6): induced voltage obtained from (3) where $\mu_{r}$ is replaced by $\mu_{r g}$ given in (6).

Our proposed Model (11): induced voltage obtained from (3) where $\mu_{r}$ is replaced by $\mu_{r g n}$ given in (11)

In all theoretical analyses, we used $\mu_{r}=10^{5}$, mu-metal thickness $h=n \cdot d$ and distance $r=D_{i} / 2$. The values of the parameters $D_{0}, D_{i}$, and $l_{m}$ used in Models (4), (6), and (11) are listed in Table IV in the Appendix .

\section{A. Induced AC Voltage Performance}

A prototype energy coupler was fabricated with $N=$ 280 turns and $n=5$ layers of mu-metal. The width $(w)$, length and thickness $(d)$ of each mu-metal layer was $50 \mathrm{~mm}, 45 \mathrm{~mm}$, and 4 mils $(0.1016 \mathrm{~mm})$, respectively. The thickness $(T)$ of the core including the interlayer air gaps was $0.78 \mathrm{~mm}$. Fig. 6 shows the experimental setup that was used to measure the induced ac voltage across the coil terminals. A lamp board consisting of eight parallel 200-W light bulbs draws current from a $120 \mathrm{~V}$, $60 \mathrm{~Hz}$ supply main. Each light bulb can be individually turned on or off and hence the current through the primary conductor can be varied. Total 5 turns $\left(N_{p}\right)$ of an insulated primary current carrying conductor were passed through the coil aperture and the maximum current flow through the primary conductor measured using an ac ammeter was $I=13.5$ A. Multiple turns of the primary conductor were passed through the energy coupler aperture in order to create a large primary magnetic flux. A 
TABLE I

COMPARISON BETWEEN THEORETICAL AND EXPERIMENTAL RESULTS. PARAMETERS: $n=5, w=50 \mathrm{~mm}, d=0.1016 \mathrm{~mm}, N=280$, $T=0.78 \mathrm{~mm}, I=13.5 \mathrm{~A}, f=60 \mathrm{~Hz}, N_{p}=5, \mu_{r}=10^{5}$ (FOR OTHER PARAMETERS PLEASE SEe TABLE IV)

\begin{tabular}{|l|l|l|l|}
\hline $\begin{array}{l}\text { Core } \\
\text { gap, } \\
\text { mm }\end{array}$ & $\begin{array}{l}\text { Energy coupler output rms ac } \\
\text { voltage (V) }\end{array}$ & $\begin{array}{l}\text { Error } \\
(\%)\end{array}$ \\
\cline { 2 - 3 } & $\begin{array}{l}\text { Theoretical } \\
\text { (Model (11)) }\end{array}$ & Measured & \\
\hline 1 & 0.825 & 0.760 & 7.9 \\
\hline 2 & 0.633 & 0.577 & 8.9 \\
\hline 3 & 0.539 & 0.485 & 10.0 \\
\hline 4 & 0.476 & 0.420 & 11.9 \\
\hline 5 & 0.430 & 0.373 & 13.3 \\
\hline 6 & 0.393 & 0.330 & 16.1 \\
\hline
\end{tabular}

better view of this is given in the inset photo in Fig. 6. The coil terminals were directly connected to a digital multimeter to measure the no load ac voltage.

Harvested ac output voltages across the coil terminals were measured by varying a number of parameters, such as, the core gap $\left(l_{g}\right)$, the number of core layers $(n)$, the core width $(w)$, the number of turns $(N)$, and the current $(I)$ in the primary conductor(s) etc. Since $l_{g}$ is an important parameter we first compare our measurement results with the results obtained using our proposed theoretical Model (11). In the theoretical analysis the same above parameters were used for the energy coupler along with $\mu_{r}=10^{5}$. Table I shows the comparison between the measured and theoretical rms ac voltages across the coil terminals as function of $l_{g}$. Since it was difficult to create $l_{g}<1 \mathrm{~mm}$ the smallest value for which experiments were performed was $l_{g}=1 \mathrm{~mm}$. As apparent, increasing $l_{g}$ decreases the output voltage. This is expected since larger $l_{g}$ means higher reluctance and lower effective permeability, $\mu_{r g n}$. For six different $l_{g}$ values, the theoretical data closely follow the measured data. As $l_{g}$ varies from 1 to $3 \mathrm{~mm}$ the percentage error (defined as the percent difference between the measured and the theoretical data) is less than $10 \%$. For $l_{g}>3 \mathrm{~mm}$, the percentage error increases. This may be due to the fact that $l_{g}$ becomes comparable to the width of the air gap $(w)$ and $b / l_{g}$ is less than 5 .

To further verify the results, we constructed another coil but changed the core width $(w)$ to $90 \mathrm{~mm}$ and measured the output rms ac voltages as function of $l_{g}$. These results are shown in Fig. 7. The theoretical voltages obtained using Models (4) and (6) are also shown for comparison. As seen Models (4) and (6) cannot approximate the measured results closely. Only Model (11) approximates the results within $10 \%$ error for $l_{g}<4 \mathrm{~mm}$.

Since the output ac voltage is dependent on $T$ which in turn relies on $n$, therefore output ac voltages were measured for 1 , 3,5 , and 8 layers $(n)$ of the core material. The corresponding measured $T$ values were $0.16 \mathrm{~mm}, 0.481 \mathrm{~mm}, 0.78 \mathrm{~mm}$ and $1.25 \mathrm{~mm}$, respectively. The theoretical and measured results are shown in Fig. 8. According to (3), the output ac voltage is expected to increase with the increase in the number of core layers $(n)$. We see such results in Fig. 8. One important observation here is that the slope of the curves for Model (4) and Model (6) are steeper than those for Model (11) and the experimental results. This is because Models (4) and (6) disregard the interlayer air gaps and hence the effective permeabilities calculated in these models are higher than the effective permeability used

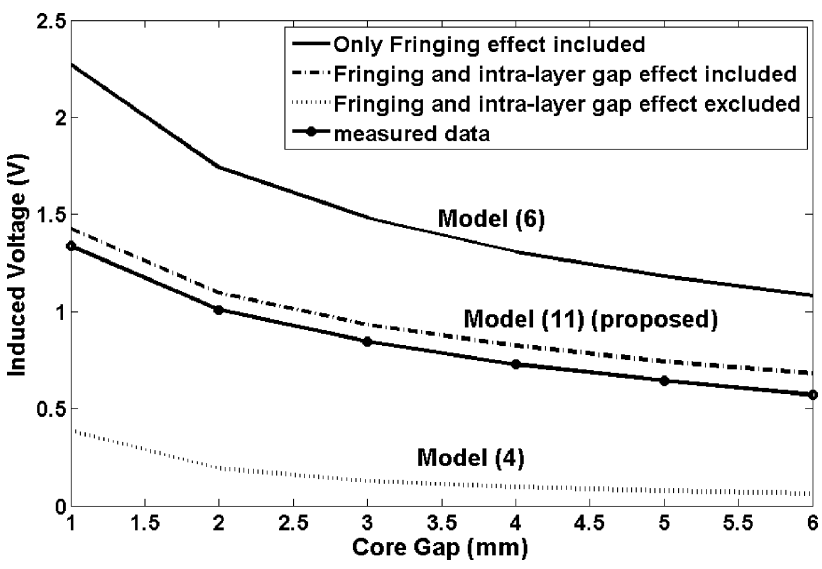

Fig. 7. Theoretical and measured voltages versus core gap $\left(l_{g}\right)$. Parameters: $n=5, w=90 \mathrm{~mm}, d=0.1016 \mathrm{~mm}, N=280, T=0.78 \mathrm{~mm}, I=$ $13.5 \mathrm{~A}, f=60 \mathrm{~Hz}, N_{p}=5, \mu_{r}=10^{5}$ (for other parameters please see Table IV).

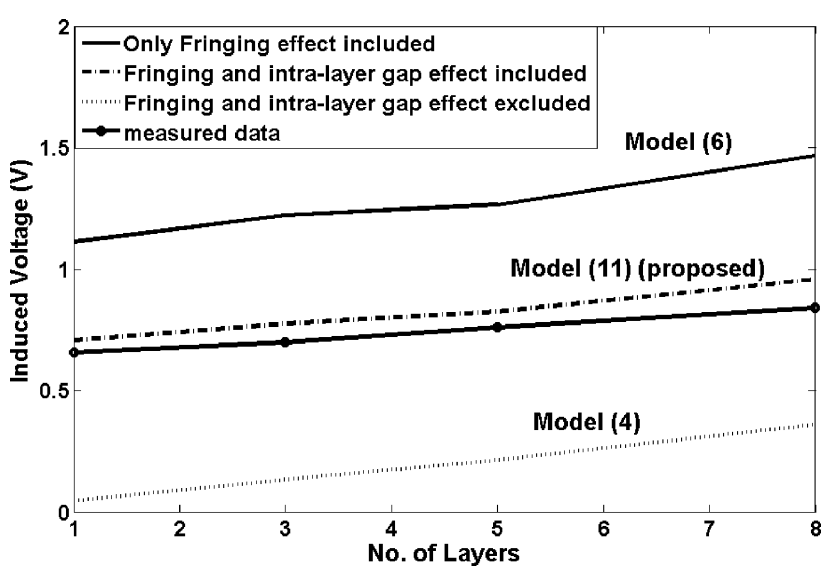

Fig. 8. Theoretical and measured voltages versus the number of core layers (n). Parameters: $l_{g}=1 \mathrm{~mm}, w=50 \mathrm{~mm}, d=0.1016 \mathrm{~mm}, N=280$, $I=13.5 \mathrm{~A}, f=60 \mathrm{~Hz}, N_{p}=5, \mu_{r}=10^{5}$ (for other parameters please see Table IV).

in Model (11). With the increase in the number of layers, the number of interlayer air gaps increases which causes the effective permeability to decrease and hence results in a smaller slope in Model (11) and in the experimental curve.

Another factor that can be changed to vary the output ac voltage is the width $(w)$ of the core layer. Measurements were also made by varying $w$ from $30 \mathrm{~mm}$ to $90 \mathrm{~mm}$ with $20-\mathrm{mm}$ steps. Fig. 9 shows the corresponding measured voltages, which are $0.449 \mathrm{~V}, 0.76 \mathrm{~V}, 1.039 \mathrm{~V}$ and $1.34 \mathrm{~V}$, respectively. The calculated data using Model (11) are $0.4987 \mathrm{~V}, 0.8266 \mathrm{~V}, 1.1545 \mathrm{~V}$, and $1.4824 \mathrm{~V}$, respectively.

It is expected that the output voltage should increase with the increase in $N$. To verify this we varied $N$ and measured the output voltage variation which is given in Fig. 10. Measurements were done for $N=100,150,200$ and 280. Corresponding measured output voltages were $0.27 \mathrm{~V}, 0.4 \mathrm{~V}, 0.539 \mathrm{~V}$ and $0.76 \mathrm{~V}$, respectively. The calculated data found from Model (11) were $0.2948 \mathrm{~V}, 0.4422 \mathrm{~V}, 0.5896 \mathrm{~V}$ and $0.8255 \mathrm{~V}$, respectively. The variation of the output voltage is linear with $w$ and $N$.

In a power system, power line conductors carry hundreds or even thousands of amperes of current and hence current carrying 


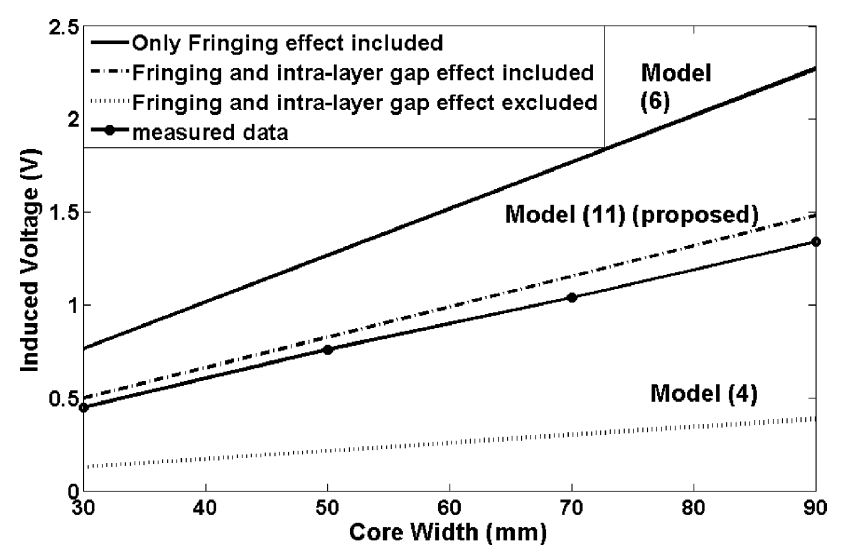

Fig. 9. Theoretical and measured voltages versus the width of core layers $(w)$. Parameters: $\mathrm{n}=5, l_{g}=1 \mathrm{~mm}, d=0.1016 \mathrm{~mm}, N=280, I=13.5 \mathrm{~A}$, $f=60 \mathrm{~Hz}, T=0.78 \mathrm{~mm}, N_{p}=5, \mu_{r}=10^{5}$ (for other parameters please see Table IV).

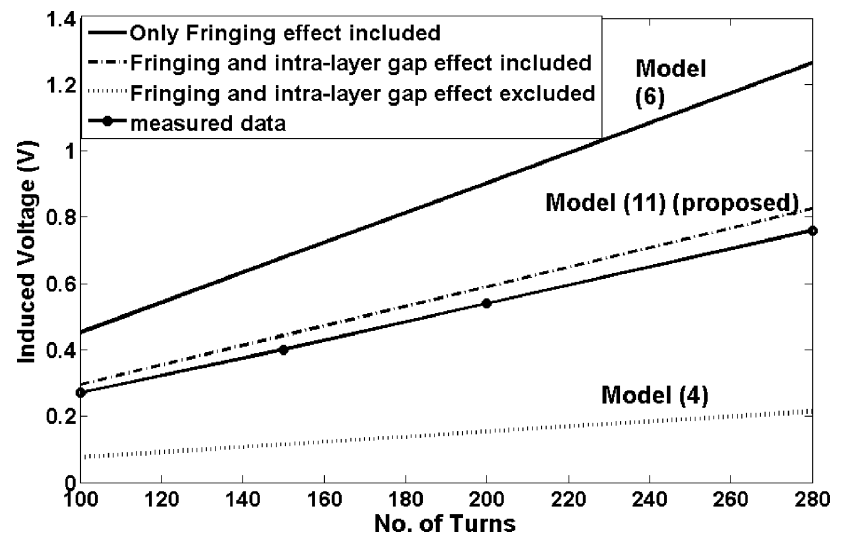

Fig. 10. Theoretical and measured voltages versus the number of turns $(N)$. Parameters: $\mathrm{n}=5, l_{g}=1 \mathrm{~mm}, d=0.1016 \mathrm{~mm}, w=50 \mathrm{~mm}, I=13.5 \mathrm{~A}$, $f=60 \mathrm{~Hz}, T=0.78 \mathrm{~mm}, N_{p}=5, \mu_{r}=10^{5}$ (for other parameters please see Table IV).

conductors have to be fat and low resistance to allow that. It is rather difficult to attain such high currents in a laboratory setting. To test the efficacy of the energy coupler in terms of its ability to have an induced voltage we developed a multi-turn looping scheme which was passed through the coupler coil. Essentially the more the number of turns in the looping scheme the higher was the magnetic field. Thus the magnetic field generated by $N_{p}$ turns of the current carrying conductor containing $I$ amperes of current is equivalent to the magnetic field generated by $N_{p} I$ amperes of current. We fabricated a prototype energy coupler and measured the effects of $N_{p}$ and $I$ on its induced voltage. The parameters of the energy coupler were as follows: $w=50 \mathrm{~mm}, n=8, T=1.25 \mathrm{~mm}, N=280, l_{g}=1 \mathrm{~mm}$, $d=0.1016 \mathrm{~mm}, f=60 \mathrm{~Hz}$, and $\mu_{r}=10^{5}$. Other parameters are listed in Table IV. Fig. 11 shows the effects of $N_{p}$ and $I$ on the no load output ac voltage of the energy coupler. We see that the output voltage increases as either $N_{p}$ or $I$ increases. The increase in the induced voltage is linear when there is only one turn passing through the aperture of the energy coupler. For 2 to 5 turns there are some nonlinearities visible especially for small $I$. This may be due to measurement error caused by slight movement of the coil with respect to the primary current carrying conductor.

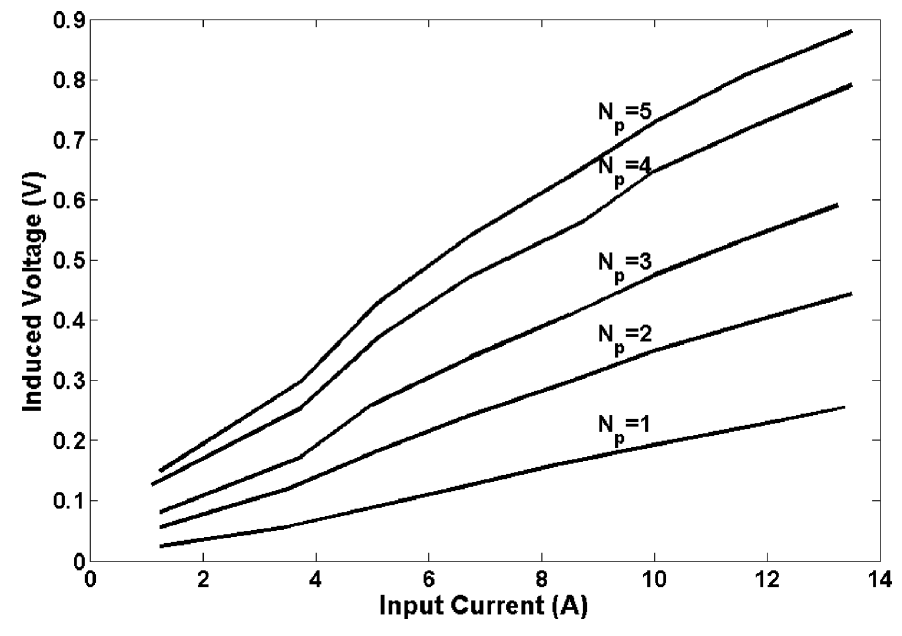

Fig. 11. Measured induced voltages versus currents $(I)$ with number of turns $\left(N_{p}\right)$ of the primary current conductor as a parameter. Parameters: $w=50 \mathrm{~mm}$, $n=8, T=1.25 \mathrm{~mm}, N=280, l_{g}=1 \mathrm{~mm}, d=0.1016 \mathrm{~mm}, f=60 \mathrm{~Hz}$, and $\mu_{r}=10^{5}$.

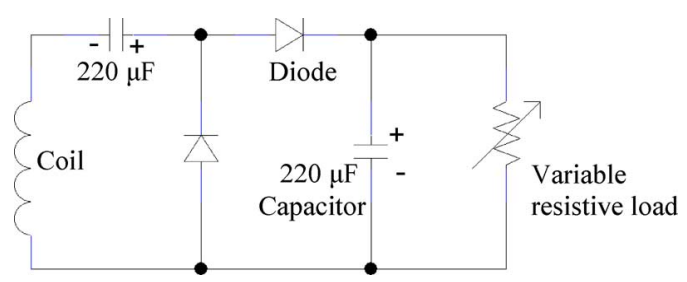

Fig. 12. Circuit diagram of the coil and the voltage multiplier with a variable resistive load.

\section{B. DC Output Performance}

In this section we discuss the dc output performance of the energy coupler. The experimental setup here is similar to the one shown in Fig. 6 except that the digital multimeter was disconnected from the coil terminals and a variable resistive load was added. Fig. 12 shows the circuit diagram of the voltage multiplier connected across the coil terminals. The number of primary conductor turns $\left(N_{p}\right)$ passing through the aperture was 5 . The parameters of the energy coupler were as follows: $w=50 \mathrm{~mm}$, $n=8, T=1.25 \mathrm{~mm}, l_{g}=1 \mathrm{~mm}, N=280, d=0.1016 \mathrm{~mm}$, $I=13.5 \mathrm{~A}, f=60 \mathrm{~Hz}, N_{p}=5$, and $\mu_{r}=10^{5}$. Like a rectifier, the voltage multiplier converts the induced ac voltage into $\mathrm{dc}$ voltage but unlike a rectifier it also increases the output $\mathrm{dc}$ voltage. The diode voltage drop is a critical factor at low input voltage levels. Regular silicon and germanium diodes have forward voltage drops of $0.7 \mathrm{~V}$ and $0.3 \mathrm{~V}$, respectively. The output ac voltage at the coil terminals is typically $0.88 \mathrm{~V}$ (rms). So if regular diodes are used the output dc voltage will be too low. Therefore, we needed very low forward voltage drop diodes. We used two very low forward voltage drop (typically $0.1 \mathrm{~V}$ at $10 \mathrm{~mA}$ ) surface mount chip diodes (model \# PMEG1020EA) and two $220 \mu \mathrm{F}$ surface mount chip tantalum capacitors (model \# 572D227X06R3B2T) to construct the voltage multiplier circuit. The multiplier was fabricated by soldering the diodes and the capacitors on a 4 mil thick flexible polyimide substrate. The multiplier gives an output dc voltage which is a multiple of the input peak voltage minus the diode drops. The measured dc 


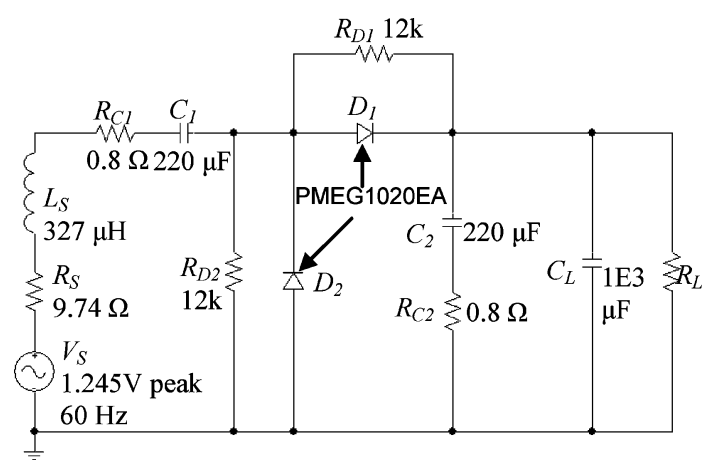

Fig. 13. PSpice model for the coil and the voltage multiplier with a resistive load.

output of the multiplier was $2.4 \mathrm{~V}$ which was about twice the input peak voltage.

Simulations and measurements were performed to determine how much power can be delivered to different resistive loads. For simulations, PSpice optimization tool was used to determine the optimum load resistance and optimum output dc power. Fig. 13 shows the PSpice model used for the optimization. Note that unlike Fig. 12, in this figure the coil is replaced by a voltage source $\left(V_{S}\right)$, a source resistance $\left(R_{S}\right)$ and a source inductance $\left(L_{S}\right)$. The source resistance (in ohm) can be found as

$$
R_{S}=\frac{l_{\text {wire }}}{\sigma A_{\text {wire }}}
$$

where $l_{\text {wire }}, A_{\text {wire }}$ and $\sigma$ are the total length, cross sectional area and conductivity of the coil wire, respectively. The source inductance (in $\mathrm{nH}$ ) is found as [34]

$$
L_{S}=\frac{0.4 \pi N^{2} \mu_{r g n} A}{l_{m}} \times 10^{-2}
$$

where $N$ is the number of turns, $\mu_{\text {rgn }}$ is the effective core permeability, $A$ is the core cross sectional area in $\mathrm{cm}^{2}$ and $l_{m}$ is the effective length of the core in $\mathrm{cm}$. The series resistances $R_{C 1}$ and $R_{C 2}$ in Fig. 13 approximate the Equivalent Series Resistances (ESRs) of the capacitors $C_{1}$ and $C_{2}$ (respectively) at the power line frequency [35] of $60 \mathrm{~Hz}$. The parallel resistances $R_{D 1}$ and $R_{D 2}$ improve the modeling of the diodes in the reverse mode of operation [36]. The capacitance $C_{L}$ was used only in simulations to approximate the dc mode of the multimeter. $C_{L}$ bypassed any AC ripple present at the simulation output. The PSpice simulation results are summarized in Table II. Five different cases including an ideal case have been shown here. We varied the wire diameter and calculated $R_{S}$ and $L_{S}$ using (12) and (13). The PSpice optimization tool was used to determine the optimum load resistance that resulted in maximum power for each case. It can be seen that ideally it is possible to get $17.86 \mathrm{~mW}$ of output power. In practice, the output power decreases with a decrease in the wire diameter. For a 30 gauge wire which was used in the measurement, the optimum power was $10.38 \mathrm{~mW}$ which could be increased to $14.36 \mathrm{~mW}$ if a 27 gauge wire was used. However, increasing the wire diameter increases the coil height, which reflects the need for compromise between coil size and output power.
TABLE II

Simulated Optimized DC OUtPut PerformanCE of THE ENERgy COUPLER

\begin{tabular}{|c|c|c|c|c|}
\hline \multirow{2}{*}{$\begin{array}{l}\text { Wire } \\
\text { diameter, } \\
\text { AWG } \\
(\mathrm{mm})\end{array}$} & \multirow{2}{*}{$\begin{array}{l}\text { Calculated } \\
\text { source } \\
\text { resistance, } \\
R_{S}(\Omega)\end{array}$} & \multirow{2}{*}{$\begin{array}{l}\text { Calculated } \\
\text { inductance } \\
L_{S}(\mu \mathrm{H})\end{array}$} & \multicolumn{2}{|c|}{$\begin{array}{l}\text { Optimized value from } \\
\text { simulation }\end{array}$} \\
\hline & & & $\begin{array}{l}\text { Load } \\
\text { resistance, } \\
R_{L}(\Omega)\end{array}$ & $\begin{array}{l}\text { output } \\
\text { power, } \\
\mathrm{mW}\end{array}$ \\
\hline Ideal case & 0 (ideal) & 0 (ideal) & 58.01 & 17.86 \\
\hline $27(0.361)$ & 4.86 & 327 & 73.39 & 14.36 \\
\hline $30(0.255)$ & 9.74 & 327 & 76.09 & 10.38 \\
\hline $33(0.18)$ & 19.54 & 327 & 118.23 & 6.21 \\
\hline $36(0.127)$ & 39.25 & 327 & 233.89 & 3.3 \\
\hline
\end{tabular}
FOR DIFFERENT DiAMETERS OF THE COIL WIRE

TABLE III

COMPARISON OF SiMULATED AND MEASURED DC OUTPUT VOLTAGE AND CURRENT

\begin{tabular}{|l|l|l|l|l|}
\hline \multirow{2}{*}{$\begin{array}{l}\text { Load } \\
\text { resistance }\end{array}$} & \multicolumn{2}{|c|}{ Simulated results } & \multicolumn{2}{c|}{ Measured results } \\
\cline { 2 - 5 }$(\Omega)$ & $\begin{array}{l}\text { Load } \\
\text { voltage (V) }\end{array}$ & $\begin{array}{l}\text { Load } \\
\text { Current } \\
(\mathrm{mA})\end{array}$ & $\begin{array}{l}\text { Load } \\
\text { voltage (V) }\end{array}$ & $\begin{array}{l}\text { Load } \\
\text { Current } \\
(\mathrm{mA})\end{array}$ \\
\hline 0.49 & 0.0109 & 22.25 & 0.009 & 23.19 \\
\hline 1.00 & 0.0222 & 22.1 & 0.02 & 22.14 \\
\hline 5.01 & 0.106 & 21.1 & 0.105 & 21.4 \\
\hline 9.99 & 0.199 & 19.9 & 0.199 & 19.99 \\
\hline 25.09 & 0.427 & 17.03 & 0.432 & 17.06 \\
\hline 50 & 0.695 & 13.87 & 0.71 & 14.03 \\
\hline 75 & 0.879 & 11.72 & 0.861 & 11.98 \\
\hline 196.1 & 1.335 & 6.81 & 1.29 & 6.84 \\
\hline 299.6 & 1.513 & 5.05 & 1.51 & 4.9 \\
\hline
\end{tabular}

Measurements were also made to determine the dc output performance of the multiplier circuit connected to resistive loads. A Tektronix DMM916 multimeter was used as an ammeter in series with the load to measure the load current. To ensure that the impedance of the DMM916 ammeter and the wire junctions do not affect the output voltage at the low load resistance level (e.g., $R_{L} \leq 1 \Omega$ ) we removed the ammeter and then connected a Tektronix CDM250 multimeter as a voltmeter across the load. A 30 gauge coil wire was used. Table III gives the PSpice simulation and measurement results for different load resistances. We observe that the output dc voltage is very low for small load resistance values. This is because of the loading effect. Fig. 14 shows the comparison between the simulated and the measured dc output power. The output dc power increases with increase in the load resistance for up to $R_{L}=76 \Omega$ after which the output power decreases. Simulated maximum dc power is $10.385 \mathrm{~mW}$ with $R_{L}=76.09 \Omega$ whereas measured maximum dc power is $10.358 \mathrm{~mW}$ obtained with $R_{L}=76.1 \Omega$. The dc power is about $10 \mathrm{~mW}$ when $R_{L}$ is in the range of 50 to $100 \Omega$. So these results imply that the designed prototype is capable of delivering the maximum dc power to devices with input impedances in the range of 50 to $100 \Omega$. The dc output power could also be improved by optimizing the multiplier circuit design. Multiplier optimization techniques are already available in the literature [37], [38] and hence is not addressed here.

Next the battery charging capability of the energy coupler was experimentally investigated. The circuit diagram is similar to that in Fig. 12 except the variable load was replaced by a Varta (model \# V250h) $1.2 \mathrm{~V}$ rechargeable battery [39]. The 


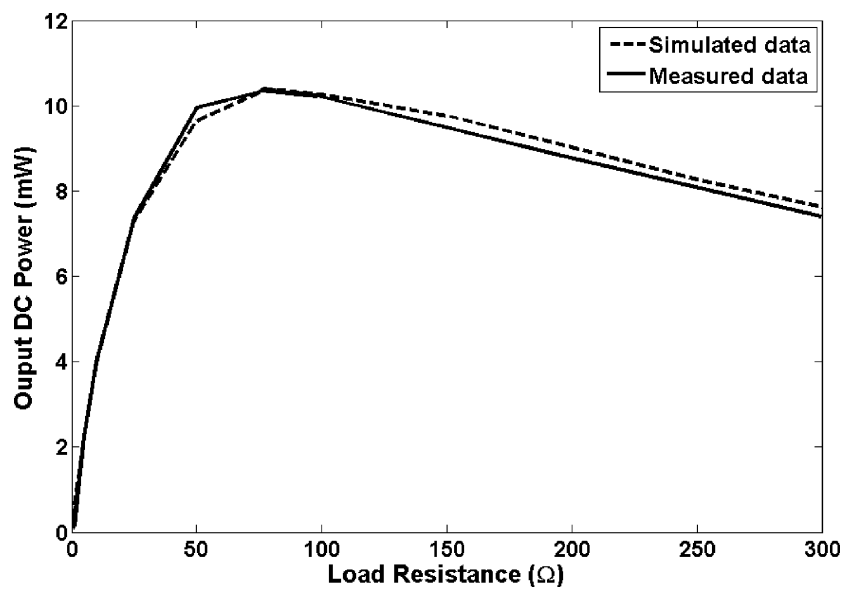

Fig. 14. Simulated and measured dc output power of the voltage multiplier as function of load resistance.

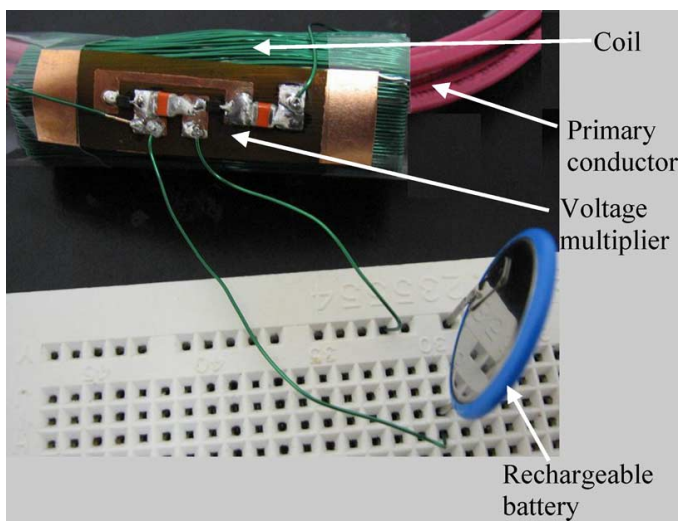

Fig. 15. Energy coupler charging a battery.

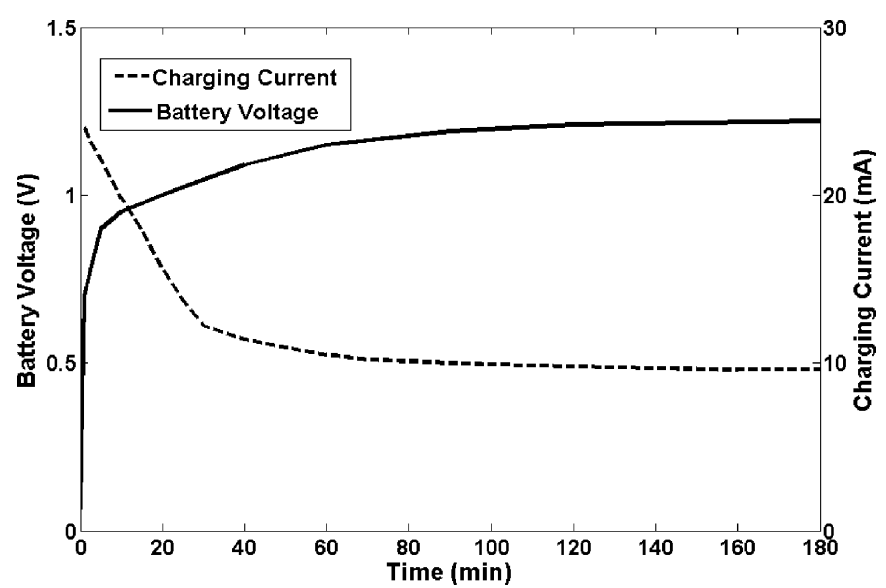

Fig. 16. Battery charging profile-battery voltage and charging current versus charging time.

battery has a capacity of $250 \mathrm{mAh}$. The rechargeable battery was first fully discharged and then connected across the voltage multiplier output, as shown in Fig. 15. Fig. 16 shows the battery charging profile as function of time. The battery voltage increases rapidly in the first $60 \mathrm{~min}$ and it reaches $1.2 \mathrm{~V}$ slowly in approximately $3 \mathrm{~h}$ (180 $\mathrm{min})$.

The charging current is as high as $24.2 \mathrm{~mA}$ at the instant when the battery is just connected to the voltage multiplier but it decreases as the battery voltages develops. The charging current settles around $10 \mathrm{~mA}$ when battery voltage reaches $1.2 \mathrm{~V}$. The manufacturer recommends charging the battery for 14-16 $\mathrm{h}$ at a constant charging current of $24 \mathrm{~mA}$ for the full capacity of $250 \mathrm{mAh}$. However, the charging profile in Fig. 16 represents a constant voltage charging method (because the energy coupler provides a constant voltage) rather than constant current charging method as specified by the manufacturer. In constant voltage charging, the charging current is determined by the voltage difference between the charger (energy coupler plus multiplier here) and the battery. During the initial period the current starts at a relatively high value then decays quickly whereas the voltage increases rapidly as charging proceeds. In the constant voltage charging method the battery quickly attains partial charge. To obtain full charge in this method somewhat longer charging time will be needed compared to other charging methods [40], [41]. Thus according to Fig. 16 approximately $24 \mathrm{~h}$ will be needed to charge the battery to its full capacity. However, in most sensor devices, batteries are rarely charged from its fully discharged state. Instead batteries are pre-charged during installation and trickle charged during operation. From the manufacturer's datasheet, the trickle charging current recommended for the battery is $7.2 \mathrm{~mA}$. From Fig. 16, it is evident that the energy coupler can meet the trickle charge current requirement of the battery.

\section{CONCLUSION}

In this paper, a novel energy coupler is presented which can harvest energy from a power line. The energy coupler was fabricated by winding numerous turns of very thin conducting wires around a core made by shaping a few layers of flexible magnetic materials (mu-metals). Tens or hundreds of turns may be required depending on the available power line current and the required power for the wireless sensor. Since the laminated core material is flexible, the intentional core gap allows the coil to be wrapped around any cylindrical or square shaped geometry like a power line cable or insulated bus bar. The target use of the energy coupler is to charge the battery of a wireless sensor which will monitor line conditions such as short circuit, open circuit, insulation damage, sag etc. and then will transmit such data to a nearby supervisory station. Unlike other ultra-low power (in $\mu \mathrm{W}$ ) energy harvesters that have been proposed in the literature our proposed energy coupler can harvest tens of milliwatts of power from power transmission lines. The induced voltage can be optimized by varying the number of coil turns, coil wire diameter, core width and the number of layers of the core magnetic material. Conversely a single energy coupler can be designed and developed which will be able to function near power lines carrying currents from 70 A to say 1000 A. For very high currents further studies may be required to ensure that magnetic saturation does not deteriorate the induced voltage.

The theoretical model proposed for the energy coupler gives a close approximation of the measured results. The theoretical values were calculated by measuring $T$ and $l_{m}$. Since in the laboratory environment, it was not possible to maintain the uniformity of $T$ and $l_{m}$, so a few measurements were taken and averages were calculated and used. This could be a source of the discrepancy between the theoretical and measured voltages. 
TABLE IV

VALUES OF THE PARAMETERS $D_{0}, D_{i}$ AND $l_{m}$ With ResPeCt TO Number OF LAYERS $(n)$ IN THE CORE, CORE WIDTH $(w)$ AND CORE GAP $\left(l_{g}\right)$

\begin{tabular}{|c|c|c|c|c|c|}
\hline$n$ & $w(\mathrm{~cm})$ & $l_{g}(\mathrm{~mm})$ & $D_{0}(\mathrm{~mm})$ & $\begin{array}{l}D_{i} \\
(\mathrm{~mm})\end{array}$ & $\begin{array}{l}l_{m} \\
(\mathrm{~mm})\end{array}$ \\
\hline 8 & 5 & 1 & 16.3 & 14.32 & 47.03 \\
\hline \multirow{6}{*}{5} & \multirow{6}{*}{5} & 1 & 16.1 & 14.5 & 47.02 \\
\hline & & 2 & 15.95 & 14.37 & 45.58 \\
\hline & & 3 & 15.99 & 14.45 & 44.77 \\
\hline & & 4 & 16.19 & 14.61 & 44.34 \\
\hline & & 5 & 15.97 & 14.42 & 42.7 \\
\hline & & 6 & 15.88 & 14.3 & 41.36 \\
\hline \multirow{6}{*}{5} & \multirow{6}{*}{9} & 1 & 15.97 & 14.41 & 46.68 \\
\hline & & 2 & 16.2 & 14.53 & 46.22 \\
\hline & & 3 & 16.12 & 14.49 & 45.04 \\
\hline & & 4 & 15.95 & 14.34 & 43.53 \\
\hline & & 5 & 16.16 & 14.55 & 43.2 \\
\hline & & 6 & 15.91 & 14.31 & 41.43 \\
\hline 3 & 5 & 1 & 15.15 & 14.45 & 45.5 \\
\hline 1 & 5 & 1 & 14.51 & 14.33 & 44.30 \\
\hline
\end{tabular}

Nevertheless the error margin is $10 \%$ which is not significant at the low output voltage level of the energy coupler.

The proposed energy coupler is small, flexible, and robust and hence can be easily placed on a power line. The coil wire, the mu-metal foils, the polyimide substrate, and the diodes used are low cost. Besides power system application, the proposed coupler has good potentials for application in miniature wireless devices where power need to be harvested from a nearby current carrying conductor without any physical connection to it.

\section{APPENDIX}

The values of the parameters $D_{0}, D_{i}$, and $l_{m}$ used in Models (4), (6), and (11) are listed in Table IV.

\section{REFERENCES}

[1] Y. Chee, M. Koplow, M. Mark, N. Pletcher, M. Seeman, F. Burghardt, D. Steingart, J. Rabaey, P. Wright, and S. Sanders, "PicoCube: A $1 \mathrm{~cm}^{3}$ sensor node powered by harvested energy," in Proc. 45th ACM/IEEE Design Auto. Conf., Jun. 2008, pp. 114-119.

[2] J. Ansari, D. Pankin, and P. Mahonen, "Radio-triggered wake-ups with addressing capabilities for extremely low power sensor network applications," in Proc. IEEE 19th Inter. Sym. Per., Ind. Mob. Radio Commun., Sep. 2008, pp. 1-5.

[3] [Online]. Available: focus.ti.com/lit/ds/symlink/cc1000.pdf

[4] J. Polastre, R. Szewczyk, C. Sharp, and D. Culler, "The mote revolution: Low power wireless sensor network devices," in Proc. Hot Chips 16: A Symp. High Perform. Chips, Aug. 2004.

[5] J. F. Randall, "On Ambient Energy Sources for Powering Indoor Electronic Devices," Ph.D. dissertation, Ecole Polytech. Fed. de Lausanne, Lausanne, Switzerland, 2003.

[6] J. M. H. Lee, S. C. L. Yuen, J. L. Wen, and P. H. W. Leong, "Development of an AA size energy transducer with micro resonators," in Proc. IEEE Int. Sym. On Circuit Syst., Thailand, May 2003.

[7] N. S. Shenck and J. A. Paradiso, "Energy scavenging with shoe-mounted piezoelectrics," IEEE Micro., vol. 21, pp. 30-41, May/Jun. 2001.

[8] M. Stordeur and I. Stark, "Low power thermoelectric generator - Selfsufficient energy supply for micro systems," in Proc. 16th Int. Conf. Therm., 1997, pp. 575-577.

[9] C. B. Williams, C. Shearwood, M. A. Harradine, P. H. Mellor, T. S. Birch, and R. B. Yates, "Development of an electromagnetic microgenerator," Proc. Inst. Elect. Eng., vol. 148, no. 6, pp. 337-342, Dec. 2001.

[10] S. Meninger, J. O. Mur-Miranda, R. Amirtharajah, A. P. Chandrakasan, and J. H. Lang, "Vibration-to-electric energy conversion," IEEE Trans. VLSI Syst., vol. 9, pp. 64-76, 2001.
[11] G. K. Ottman, H. F. Hofmann, and G. A. Lesieutre, "Optimized piezoelectric energy harvesting circuit using step-down converter in discontinuous conduction mode," IEEE Trans Power Electron., vol. 18, no. 2, pp. 696-703, 2003.

[12] E. S. Leland, R. M. White, and P. K. Wright, "Energy scavenging power sources for household electrical monitoring," in Proc. PowerMEMS, Berkeley, CA, Nov.-Dec. 29-1, 2006.

[13] J. Hirai, T. Kim, and A. Kawamura, "Wireless transmission of power and information and information for cableless linear motor drive," IEEE Trans. Power Electron., vol. 15, pp. 21-27, Jan. 2000.

[14] P. Sergeant and A. V. Bossche, "Inductive coupler for contactless power transmission," IET Electr. Power Applicat., vol. 2, no. 1, pp. $1-7$, Jan. 2008.

[15] K. Finkenzeller, RFID Handbook: Fundamentals and Applications in Contactless Smart Cards and Identification, 2nd ed. New York: Wiley, 2003.

[16] A. Kurs, A. Karalis, R. Moffatt, J. D. Joannopoulos, P. Fisher, and M. Soljacic, "Wireless power transfer via strongly coupled magnetic resonances," Science, vol. 317, no. 5834, pp. 83-86, Jul. 2007.

[17] H. Zangl, A. Fuchs, T. Bretterklieber, M. Moser, and G. Holler, "An investigation on wireless communication and power supply through metal tank walls," in Proc. IEEE Conf. Proc. Instrum. Meas. Technol. Conf., May 2008, pp. 1452-1457.

[18] C. Sauer, M. Stanacevic, G. Cauwenberghs, and N. Thakor, "Power harvesting and telemetry in CMOS for implanted devices," IEEE Trans. Circuits Syst I, vol. 52, no. 12, pp. 2605-2613, Dec. 2005.

[19] M. Catrysse, R. Puers, C. Hertleer, L. V. Langenhove, H. V. Egmond, and D. Matthys, "Towards the integration of textile sensors in a wireless monitoring suit," Sens. Actuators A, vol. 114, no. 2-3, pp. 302-311, Sep. 2004.

[20] M. Catrysse, B. Hermans, and R. Puers, "An inductive power system with integrated bi-directional data-transmission," Sens. Actuators A, vol. 115 , no. $2-3$, pp. 221-229, Sep. 2004.

[21] O. Chevalerias, T. O'Donnell, D. Power, N. O'Donovan, G. Duffy, G. Grant, and S. C. O'Mathuna, "Inductive telemetry of multiple sensor modules," IEEE Pervasive Comput., vol. 4, no. 1, pp. 46-52, Jan.-Mar. 2005.

[22] P. H. Dietz, D. Leigh, and W. S. Yerazunis, "Wireless liquid level sensing for restaurant applications," in Proc. IEEE Sensors, 2002, vol. 1, pp. 715-720.

[23] P. G. Halverson, S. J. Syracuse 1, R. Clark, and F. M. Tesche, "Non-contact sensor system for real-time high-accuracy monitoring of overhead transmission lines," in Proc. EPRI Conf. Overhead Trans. Lines, Mar. 2008.

[24] N. D. Sadanandan and A. H. Eltom, "Power donut system laboratory test and data analysis," in Proc. IEEE Proc. Southeastcon '90, Apr. 1990, vol. 2, pp. 675-679.

[25] [Online]. Available: http://www.usi-power.com/Products $\% 20 \& \% 20$ Services/Donut/PowerDonut2\%20Cell.pdf

[26] L. Ferkovíc, D. Ilíc, and R. Malaríc, "Mutual inductance of a precise Rogowski coil in dependence of the position of primary conductor,' IEEE Trans. Instrum. Meas., vol. 58, no. 1, pp. 122-128, Jan. 2009.

[27] V. Dubickas and H. Edin, "High-frequency model of the Rogowski coil with a small number of turns," IEEE Trans. Instrum. Meas., vol. 56, no. 6, pp. 2284-2288, Dec. 2007.

[28] C. Qing, L. Hong-bin, Z. Ming-ming, and L. Yan-bin, "Design and characteristics of two Rogowski coils based on printed circuit board," IEEE Trans. Instrum. Meas., vol. 55, no. 3, pp. 939-943, Jun. 2006.

[29] W. M. Flanagan, Handbook of Transformer Design and Applications, 2nd ed. New York: McGraw-Hill, 1993.

[30] E. C. Snelling, Soft Ferrites/ Properties and Applications. London, U.K.: Iliffe, 1969.

[31] D. K. Cheng, Fundamentals of Engineering Electromagnetics. Upper Saddle River, NJ: Prentice-Hall, 1993.

[32] F. Fioeillo, Measurement and Characterization of Magnetic Materials. New York: Elsevier, 2004.

[33] H. Skarrie, "Design of Powder Core Inductors," Licentiate, Lund Univ., Dept. Indust. Elect. Eng Automat., Lund, Sweden, 2001.

[34] C. Bowick, C. Ajluni, and J. Blyler, RF Circuit Design, 2nd ed. New York: Elsevier/Newnes, 2007.

[35] S. M. Sandler and C. Hymowitz, SPICE Circuit Handbook. New York: McGraw-Hill, 2006

[36] [Online]. Available: http://www.nxp.com/models/spicespar/data/PME G1020EA.html

[37] J. S. Brugler, "Theoretical performance of voltage multiplier circuits," IEEE J. Solid State Circuits, vol. 6, no. 3, pp. 132-135, Jun. 1971. 
[38] C. Saha, T. O'Donnell, J. Godse, L. Carlioz, N. Wang, P. McCloskey, S. Beeby, J. Tudor, and R. Torah, "Step-up converter for electromagnetic vibrational energy scavenger," in Proc. Design, Test, Integration Packag. MEMS/MOEMS - DTIP 2007, Stresa, Italy, Apr. 2007.

[39] [Online]. Available: http://store.batteryspecialists.com/v250h.html

[40] Rechargeable Batteries Applications Handbook, Gates Energy Products, Newnes, 1997

[41] R. M. Dell and D. A. J. Rand, Understanding Batteries. London, U.K.: Royal Soc. Chemistry, 2001.

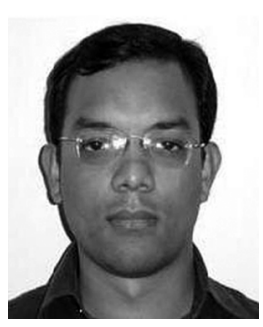

Rashed H. Bhuiyan (S'09) received the B.Sc. and M.Sc. degrees in electrical engineering from the Bangladesh University of Engineering and Technology, Dhaka, Bangladesh, in 2003 and 2005, respectively. He is currently working towards the Ph.D. degree at the Department of Electrical Engineering, University of South Carolina, Columbia.

$\mathrm{He}$ is the author of multiple international conference and journal papers. He also served as a faculty member with the Bangladesh University of Engineering and Technology, Dhaka, from 2003 to 2005. His current research interests include miniature electromagnetic sensor design, antennas, and RF circuits.

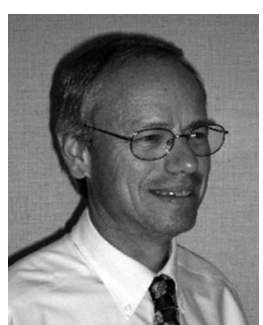

Roger A. Dougal (M'82-SM'94) received the Ph.D. degree from Texas Tech University, Lubbock, in 1983.

He leads the Power and Energy Group, Electrical Engineering Department, University of South Carolina (USC), Columbia, which has a principal research focus in the general area of power electronics. As a member of the Board of Directors of the Electric Ship Research and Development Consortium, he oversees USC's activities related to new power generation, processing, and distribution technologies for ships. He is also the Site Director for a new NSF-sponsored Industry/University Cooperative Research Center for Grid-connected Advanced Power Electronics, which is a joint project between USC and the University of Arkansas. Also, since 1996, under sponsorship of the Office of Naval Research, he has overseen development of the Virtual Test Bed software, which is a comprehensive simulation and virtual prototyping environment for multidisciplinary dynamic systems. This environment has been applied in studies of electric systems for navy ships, electrochemical power sources, hybrid power sources, power electronics, and controls.

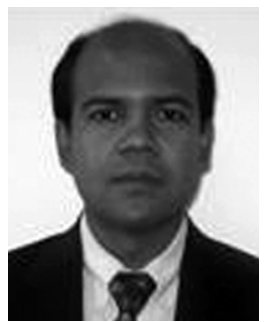

Mohammod Ali (M'93-SM'03) received the B.Sc. degree in electrical and electronic engineering from the Bangladesh University of Engineering and Technology, Dhaka, Bangladesh, in 1987, and the M.A.Sc. and Ph.D. degrees, both in electrical engineering, from the University of Victoria, Victoria, BC, Canada, in 1994 and 1997, respectively.

He was with the Bangladesh Institute of Technology, Chittagong, from 1988 to 1992. From January 1998 to August 2001, he was with Ericsson, Inc., Research Triangle Park, NC. Since August 2001, he has been with the Department of Electrical Engineering, University of South Carolina, Columbia, where currently he is an Associate Professor. He had also held appointments as a Visiting Research Scientist with the Motorola Corporate EME Research Laboratory, Plantation, FL, from June to August 2004. He established the Microwave Engineering Laboratory at the University of South Carolina in 2001. He is the author/coauthor of over 100 publications and five granted U.S. patents. His research interests include miniaturized packaged (embedded) antennas, meta-materials and their antenna applications, distributed wireless sensors and rectennas, and portable/wearable antennas and their interactions with humans (SAR).

Dr. Ali is the recipient of the 2003 National Science Foundation Faculty Career Award. He is also the recipient of the College of Engineering and Information Technology Young Investigator Award and the Research Progress Award from the University of South Carolina in 2006 and in 2008, respectively. $\mathrm{He}$ was the Technical Program Co-Chair of the IEEE Antennas and Propagation Society's International Symposium in Charleston, SC, in 2009. He has also served as a member of the Technical Program Committee for the IEEE Antennas and Propagation Society's International Symposium for a number of years. He has served as a reviewer and panelist for grant proposals for a number of federal and local funding agencies. He is an Associate Editor for the IEEE ANTENNAS AND WIRELESS PROPAGATION LETTERS. 